\title{
Ischaemic swelling of cerebral hemisphere in the gerbil
}

\author{
M. J. G. HARRISON, J. ARNOLD, L. SEDAL, AND R. W. ROSS RUSSELL \\ From the Department of Neurological Studies, The Middlesex Hospital, and the National Hospital, Queen \\ Square, London
}

SYNOPSIS Ligation of the common carotid artery in the gerbil was found to be associated with an increase in wet weight, volume, and area of the ipsilateral cerebral hemisphere. True swelling and oedema of the hemisphere occurs. This evidence suggests that it is reasonable to continue to use the gerbil as an animal model of the oedema that may accompany cerebral infarction.

Oedema accompanies cerebral infarction in man and on occasion may be of sufficient severity for the swollen hemisphere to act as a space occupying lesion (Farmer and Wood, 1956). Secondary brain-stem compression and haemorrhages may be seen in fatal cases (Berry and Alpers, 1957). While oedema of this extent is unusual, clinical observation suggests that lesser degrees of swelling may be found in $20 \%$ of patients sustaining a non-haemorrhagic stroke (Plum, 1970). The CSF pressure at lumbar puncture in those patients with clinical evidence of oedema is higher and their prognosis for survival is worse (Plum, 1970).

Therapeutic regimes aimed at reducing cerebral oedema have been claimed to benefit the acute stroke victim (Meyer et al., 1971; Patten et al., 1972). A detailed study has, however, been hampered by lack of a suitable animal model. Ischaemic damage of cerebral hemisphere tissue can be produced by combining anoxia with carotid artery ligation in the rat (Levine preparation). Spector (1961) has demonstrated the occurrence of oedema in this preparation. However, the need to combine anoxia with the carotid ligation makes this a less than ideal model of the pathophysiological situation in human thromboembolic infarction.

Ligation of the common carotid artery in the neck of the adult Mongolian gerbil (Meriones unguiculatus) causes infarction of the ipsilateral

(Accepted 9 July 1975.) cerebral hemisphere in approximately $60 \%$ of instances (Harrison and Ross Russell, 1972). The vulnerability of the brain to extracranial vessel ligation in this species is due to the incompleteness of the circle of Willis. Sixty per cent of affected animals show neurological deficit consisting of abnormal circling behaviour, rolling seizures, or splaying of the contralateral limb (Khan, 1972).

The infarcted hemisphere appears swollen within eight hours, and the percentage wet weight is increased at this time (Harrison et al., 1973). Proof that this apparent change in water content is associated with swelling of the hemisphere has been lacking, the alternative possibility being that the percentage wet weight of the brain rises due to loss of cerebral substance by necrosis. Measurements of hemisphere wet weight, volume, and cross-sectional area have therefore been made.

\section{METHOD}

The right common carotid artery was ligated in adult gerbils under pentobarbitone anaesthesia. Eight hours later the animals were killed by decapitation and the brain was removed rapidly. The two cerebral hemispheres were carefully separated from the brain-stem and from each other, and weighed immediately (wet weight).

Hemisphere volumes were then measured by calculating the weight of water displaced when the brain was suspended in a volume of water in a small beaker on a balance pan. The beaker and contents 1194 
were weighed. Each cerebral hemisphere was then suspended from a wire stand by a thin thread. As the brain tissue was immersed completely in the water, the weight of the beaker and its contents rose by an amount equal to the weight of water displaced by the immersed cerebral hemisphere.

In another series of animals the brain was fixed in formol saline and a single coronal section was taken through the optic chiasm. The cross-sectional area of the hemisphere was measured by a counting squares technique under the low power of a dissecting microscope.

RESULTS

The gross weight of the right hemisphere in operated animals is greater than that of the left hemisphere (Table $1, \mathrm{P}<0.001$ ). The change is most marked in those animals showing neurological deficit, and therefore known to have an infarct. The volume of the right hemisphere in operated animals is also significantly greater, particularly in those individuals which show neurological abnormality (Table 2, P < 0.001). The cross-sectional area of the right hemisphere was also increased, though the difference is less clear cut in the small group studied (Table 3, $\mathrm{P}<0.05)$.

\section{DISCUSSION}

In a previous study, we showed that the percentage water content of the infarcted gerbil

TABLE 1

WET WEIGHT OF CEREBRAL HEMISPHERES EIGHT HOURS AFTER LIGATION OF RIGHT CAROTID ARTERY

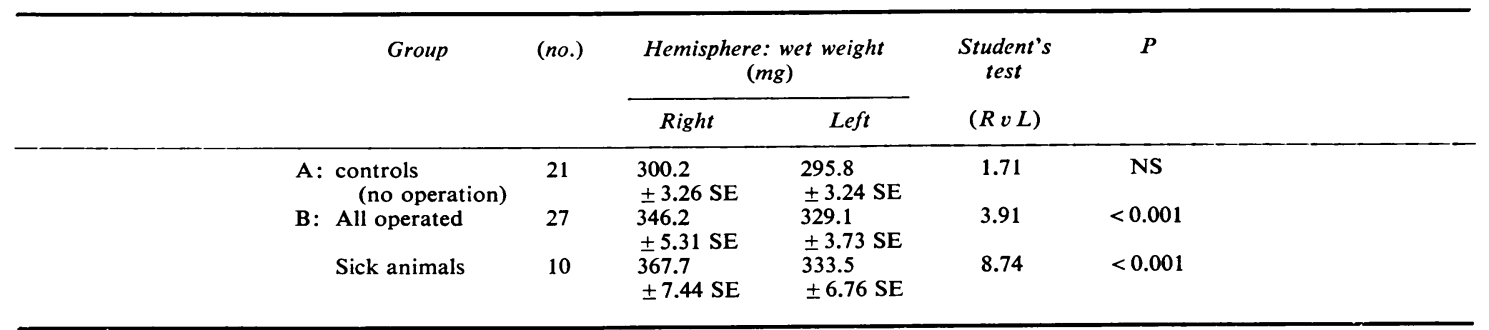

TABLE 2

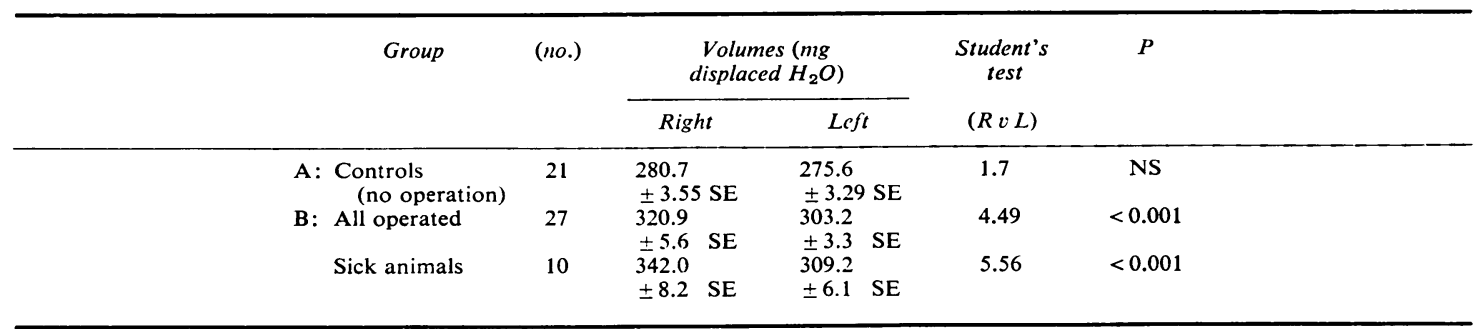

TABLE 3

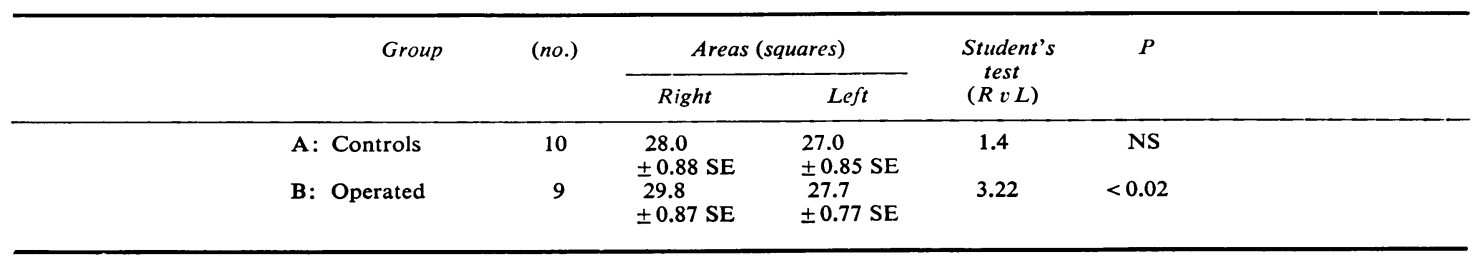


hemisphere was greater eight hours after carotid ligation (Harrison et al., 1973). The present measurements have shown that this is associated with an increase in total weight, volume, and cross-sectional area of the hemisphere. There is thus both true oedema and swelling.

Klatzo (1967) has described two types of oedema, cytotoxic and vasogenic. In the gerbil, breakdown of the blood-brain barrier after carotid ligation does not occur until 18 to 24 hours, while oedema is demonstrable within a few hours (Klatzo, 1973). This suggests that, in this preparation, the early oedema may be cytotoxic. Later, vasogenic oedema may also occur.

In the case of the cerebral infarction in man, there is little evidence on the type of oedema in the early stages. The fact that brain isotope scans do not become positive until the second week in most cases of cerebral infarction (Glasgow et al., 1965; Usher and Quinn, 1969) suggests that the blood-brain barrier in the damaged area is grossly intact at a stage when oedema is common three to four days after the onset (Shaw et al., 1959). Despite the difference in time course between the human situation and the animal model, it appears possible that, in both, oedema precedes the major breakdown of the blood-brain barrier to large molecules. The present data suggests, therefore, that it is reasonable to continue to use the gerbil as a model of ischaemic oedema and swelling of the brain tissue.

We are grateful to Dr J. Watson of the Academic Department of Radiotherapy, The Middlesex Hospital, for suggesting the method of measuring the volume of tissue samples.

\section{REFERENCES}

Berry, R. G., and Alpers, B. J. (1957). Occlusion of the carotid circulation: pathological consideration. Neurology (Minneap.), 7, 223-237.

Farmer, T. W., and Wood, E. M. (1956). Unilateral cerebral edema with thrombosis of the internal carotid or middle cerebral artery. Transactions of the American Neurological Association, 81, 105-108.

Glasgow, J. L., Currier, R. D., Goodrich, J. K., and Tutor, F. T. (1965). Brain scans at varied intervals following CVA. Journal of Nuclear Medicine, 6, 902-916.

Harrison, M. J. G., and Ross Russell, R. W. (1972). Effect of dexamethasone on experimental cerebral infarction in the gerbil. Journal of Neurology, Neurosurgery, and Psychiatry, 35, 520-521.

Harrison, M. J. G., Brownbill, D., Lewis, P. D., and Ross Russell R. W. (1973). Cerebral edema following carotid artery ligation in the gerbil. Archives of Neurology, 28, 389-391.

Khan, K. J. (1972). The natural course of experimental infarction in the gerbil. Neurology (Minneap.), 22, 510-515.

Klatzo, I. (1967). Neuropathological aspects of brain edema. Journal of Neuropathology and Experimental Neurology, 26, 1-14.

Klatzo, I. (1973). Pathophysiology of brain edema: pathological aspects. Advances in Neurosurgery, vol. 1, pp. 1-4, Springer: Berlin.

Meyer, J. S., Charney, J. Z., Rivera, V. M., and Mathew, N. T. (1971). Treatment with glycerol of cerebral oedema due to acute cerebral infarction. Lancet, 2, 993-997.

Patten, B. M., Mandel, J., Bruin, B., and Carter, S. (1972). Double blind study of the effect of dexamethasone on acute stroke. Neurology (Minneap.), 22, 377-383.

Plum, F. (1970). Edema in cerebral infarction. In Seventh Conference in Cerebral Vascular Diseases, pp. 51-54. Edited by J. F. Toole, J. Moossy, and J. Janeway. Grune and Stratton: New York.

Shaw, C-M., Alvord, E. C., and Berry, R. G. (1959). Swelling of the brain following ischemic infarction with arterial occlusion. Archives of Neurology, 1, 161-177.

Spector, R. G. (1961). Water content of the brain in anoxic ischaemic encephalopathy in adult rats. British Journal of Experimental Pathology, 42, 623-630.

Usher, M. S., and Quinn, J. L. (1969). Serial brain scanning with Technetium $99 \mathrm{~m}$ pertechnetate in cerebral infarction. American Journal of Roentgenology, 105, 728-729. 